(Notes)

\title{
The Effects of Acute Osmotic Stress on Innate Immunity of Nile Tilapia (Oreochromis niloticus)
}

\author{
Sang-Hoon Choi* and Kwan-Ha Park \\ Department of Aquatic Life Medicine, Kunsan National University, \\ Kunsan 573-400, Korea
}

\begin{abstract}
The effects of osmotic stress on the non-specific immune response of Nile tilapia, Oreochromis niloticus, were investigated. Osmoregulatory mechanism of tilapia has been studied, but less information is available about innate immune response of $O$. niloticus faced with hyperosmolality. Acute osmotic stress was elicited by transferring tilapia from freshwater (FW) to 24 psu seawater (SW). Non-specific immune parameters including lysozyme activities of plasma and head kidney (HK), alternative complement pathway (ACP) activity in plasma, phagocytic capacities of spleen and HK immune cells, and respiratory burst activity of immune cells in both HK and spleen were analyzed. Lysozyme activities were increased at $1 \mathrm{~h}$ and $30 \mathrm{~h}$ after transfer to SW, but decreased at $10 \mathrm{~h}$ after SW transfer. Conversely, ACP activity increased $10 \mathrm{~h}$ after SW transfer. Phagocytic capacity increased slightly at $1 \mathrm{~h}$ and $5 \mathrm{~h}$ after SW transfer, and respiratory burst activity showed an increase in superoxide release at $10 \mathrm{~h}$ after SW transfer. Taken together, these results indicate that the exposure of tilapia to hyperosmotic conditions has immunostimulatory effects on cellular and humoral immune reactions.
\end{abstract}

Key words: Respiratory burst activity, ACP, Phagocytosis, Lysozyme activity, Oreochromis niloticus

\section{Introduction}

Environmental stimulations such as salinity changes and sudden temperature changes exert negative effects on fish physiology, psychology, growth, and breeding (Crawshaw, 1979; Cuesta et al., 2005). Weng et al. (2002) have reported that tilapia can avoid dehydration and adapt to the hypero-smolality of seawater (SW), making tilapia ideal for investigating osmoregulation in teleosts. In the past, most studies of tilapia have focused on their osmoregulation, but knowledge of the immunological responses of fish facing hyperosmolality is limited.

Vertebrates have well-developed immune systems comprising both acquired and innate immunity; innate immunity protects hosts against invading foreign pathogens in a non-specific manner. Like tilapia (O. niloticus), other species of FW fish (catfish, Ictalurus punctatus; carp, Cyprinus carpio; rainbow trout, Oncorhynchus mykiss) have natural killer cells referred to as non-specific cytotoxic cells (NCC)

\footnotetext{
*Corresponding author: shchoi@kunsan.ac.kr
}

(Jaso-Friedmann et al., 2000). NCCs are important in providing resistance against bacterial pathogens such as Streptococcus iniae in tilapia (Taylor et al., 2001). Lysozyme, a bactericidal peptide, is an important component of the immune defenses of both FW and marine fish species (Lie et al., 1989). Increases in lysozyme activity, phagocytosis, and cell meditated cytotoxicity, and a decrease in antibody production were found in salmon during $\mathrm{FW}$ to $\mathrm{SW}$ transfer (Marc et al., 1995). Chronic exposure of tilapia to $0.53 \%$ tannery effluent (TE) at low temperature significantly reduced antibody responses, nonspecific lysozyme activity, and the production of reactive nitrogen and oxygen species (Prabakaran et al., 2007). It had been reported previously that humoral immune responses in gilthead sea bream were increased under conditions of hyperosmolality (Cuesta, et al., 2005). In tilapia, the effects of acute salinity stress on immune responses are unclear. In this study, in vivo tests were conducted to evaluate the immune responses of tilapia during environmental changes. Hence, this study aims to determine the effects of salinity stress on the phagocytic activity, 
respiratory burst (release of superoxide anions), lysozyme activity, and activity of the alternative complement pathway of tilapia, $O$. niloticus.

\section{Materials and Methods}

\section{Fish}

Nile tilapia $O$. niloticus of approximately $30-40 \mathrm{~g}$ (about 6 months old) were obtained from the fish farm at Kunsan National University and maintained in FW recirculation tanks supplied with a filter and aeration system at $22-26^{\circ} \mathrm{C}$. Approximately 60 fish were used for this experiment. For hyperosmolality (SW) challenge tests, four treatment times $(1,5,10$, and $30 \mathrm{~h}$ ) were used, with five fish per exposure time maintained in different tanks. Two additional tanks of fish were kept in FW as controls, and five fish were removed and sampled at the same times as experimental groups. At the end of the experiment, tilapia were immediately anesthetized and sacrificed on ice; blood, HK, and spleen were collected.

In all tests, the fishes were fed daily on a commercial diet (Purina, Kunsan, Korea) during the experiment. Prior to the experiments, fish were acclimated to laboratory conditions for more than 1 month, and both male and female tilapia ranging from 35 to $65 \mathrm{~g}$ (mean $\pm \mathrm{SD}=50 \pm 20 \mathrm{~g})$ with no significant differences among the SW treatments were used in these experiments. All experiments were performed according to the Guide for the Care and Use of Laboratory Animals of Kunsan National University. Twenty-two psu SW was prepared using tap water with artificial sea salt (Coral Marine Sea Salt ${ }^{\mathbb{B}}$, Aqua Craft, Inc. Products ${ }^{\circledR}$, Hayward, CA, USA). Salinity was measured using a salinity refractometer (Hand Refractometer S/Mill-E, Atago, Itabashi-Ku, Tokyo, Japan).

\section{Blood sampling}

Tests were conducted on 5 fish at each of four exposure times $(1,5,10$, and $30 \mathrm{~h})$, with fish sampled at each time point being maintained in individual tanks. Five fish per group were carefully netted and anesthetized with $0.02 \%$ benzocaine solution, and blood was collected from the caudal vessel using a syringe pretreated with heparin ammonium (400 $\mathrm{U} / \mathrm{mL}$ ) (Sigma, St. Louis, MO, USA). The majority of the collected blood was transferred to $1.5 \mathrm{~mL}$ centrifuge tubes and stored on ice. Plasma was obtained by centrifugation of blood samples at $9,600 \times g$ for $5 \mathrm{~min}$ and subsequently used for lysozyme activity and ACP analyses.

\section{Preparation of leukocytes}

Spleen and HK from both FW and SW transfer fish were used to prepare leukocytes. Cell suspensions were prepared in an RPMI-1640 (Gibco) medium by grinding cells with ground glass and filtering them through a nylon mesh. Leukocytes were separated on a 51\% Percoll gradient (Sigma) in PBS (Gibco). Cells collected at the interface were washed twice and resuspended with RPMI-1640 medium, and the cell suspensions were then centrifuged at $500 \times g$ at RT for 10 min. Finally, the cells were washed twice with PBS.

\section{Analysis of lysozyme activity}

$\mathrm{HK}$ and plasma lysozyme activity was measured in triplicate for each of five fish per sampling time. Samples $(200 \mu \mathrm{L})$ of head kidney suspension with RPMI-1640 medium in a $1.5 \mathrm{ml}$ centrifuge tube were homogenized and centrifuged at $9600 \times \mathrm{g}$ for $5 \mathrm{~min}$. The supernatant was kept for lysozyme assay. HK and plasma lysozyme activity were determined using a turbidimetric assay (Shugar, 1952). Micrococcus lysodeikticus $(0.4 \mathrm{mg} / \mathrm{mL}$; Sigma) was suspended in $0.05 \mathrm{M}$ potassium phosphate buffer $(\mathrm{pH} 6.2)$ and used as a substrate. $\mathrm{HK}$ and plasma $(10 \mu \mathrm{L})$ were added to $260 \mu \mathrm{L}$ of bacterial suspension and incubated for $5 \mathrm{~min}$ at $28 \pm 1^{\circ} \mathrm{C}$; the reduction in absorbance was measured at $490 \mathrm{~nm}$ using an automated spectrophotometer (SpectraMax 190). One unit of lysozyme activity was defined as the amount of plasma and HK required to cause a reduction in absorbance of $0.001 / \mathrm{min}$. The data are presented herein as ratios of the FW fish sampled at each experimental time \pm SD $(n=5)$.

\section{Phagocytic activity}

To measure the phagocytic activity of leukocytes, fish were transferred to $24 \mathrm{psu} \mathrm{SW}$ and to FW. At 0 , $1,5,10$, and $30 \mathrm{~h}$ after transfer, five tilapia per group were anesthetized, and the $\mathrm{HK}$ and spleen were removed; leukocytes were prepared as outlined above. Flow cytometry (Esteban et al., 1998) was used to measure the phagocytic activity of HK cells and splenocytes. To each $100 \mu \mathrm{L}$ sample of HK or spleen leukocyte suspension, aliquots of $10 \mu \mathrm{L}$ FITC-labeled Escherichia coli JM 109 (adjusted to $1 \times 10^{8}$ cells $/ \mathrm{mL}$ ) were added in $1.5 \mathrm{ml}$ tubes. The samples were then centrifuged $\left(300 \times \mathrm{g}, 5 \mathrm{~min}, 22^{\circ} \mathrm{C}\right)$, resuspended in RPMI-1640 medium, and incubated at $22^{\circ} \mathrm{C}$ for $45 \mathrm{~min}$. At the end of the incubation, the samples were placed on ice to stop phagocytosis, and $800 \mu \mathrm{L}$ of ice-cold PBS were added to each sample, and analysis by flow cytometry (Cytomics ${ }^{\mathrm{TM}}$ FC500, 
Beckman, Fullerton, CA, USA) was conducted. Instrument settings were adjusted to obtain optimal discrimination of the different cell populations present in the HK and spleen leukocyte suspensions. Only the phagocyte population was acquired by cell size and granularity and analyzed for each sample. Analyses were performed on 10,000 cells that were acquired at a rate of 300 cells/s. Data were collected in the form of two-parameter side scatter (granularity) (SSC) and forward scatter (size) (FSC) or green fluorescence (FL1) dot plots. Fluorescence histograms were obtained from a computerized system showing relative fluorescence on a logarithmic scale. Phagocytic capacity was defined as the relative number of ingested bacteria per phagocytic cell assessed from the mean fluorescence intensity of the cells. Data are presented herein as ratios of the FW fish sampled at each experimental time as mean $\pm \mathrm{SD}$ $(n=5)$.

\section{Respiratory burst assay}

The respiratory burst activity of HK and spleen leukocytes was studied by flow cytometry as previously described (Craig et al., 2005). Samples $(100 \mu \mathrm{L})$ of $\mathrm{HK}$ and spleen leukocyte suspensions were mixed with $0.05 \mathrm{M}$ dichlorofluorescein diacetate (DCFH-DA, Sigma) in the dark on a shaker platform ( $55 \mathrm{rpm})$ at room temperature for $25 \mathrm{~min}$. In the presence of reactive oxygen species, DCFH-DA is oxidized to dichlorofluorescein (DCF), which can be detected by flow cytometry, thus providing a quantitative assessment of the respiratory burst in individual cells. No stimulatory agents were added to analyze respiratory burst activity. After incubation, the cells were washed twice with cold PBS and resuspended in $500 \mu \mathrm{L}$ of cold PBS for analysis by flow cytometry, which was performed within $30 \mathrm{~min}$. Cells with a fluorescence intensity greater than background were considered positive, indicating that a respiratory burst occurred. The respiratory burst activity per cell was assessed from the mean fluorescence intensity of the cells. Data are presented herein as ratios of the $\mathrm{FW}$ fish sampled at each experimental time as mean $\pm \mathrm{SD}(n=5)$.

\section{Alternative complement activity}

The activity of the alternative complement pathway (ACP) was assayed using rabbit red blood cells (RRBC) as targets. RRBC were washed in phenol red-free HBSS (Gibco) without $\mathrm{Mg}^{2+}$ and $\mathrm{Ca}^{2+}$ and $10 \mathrm{mM}$ EGTA (Sigma) and resuspended at 3\% (v/v) in HBSS with the addition of $0.5 \mathrm{mM} \mathrm{Mg} \mathrm{Mg}^{2+}$. Plasma samples were diluted (1:50) to different volumes ranging from $0.1 \mathrm{~mL}$ to $0.25 \mathrm{~mL}$ and were dispensed into a series of test tubes. The total volume was brought up to $0.25 \mathrm{~mL}$ with the same buffer and was then added to $0.1 \mathrm{~mL}$ of RRBC suspension. After incubation for $1 \mathrm{~h}$ at $22^{\circ} \mathrm{C}$, samples were centrifuged at $300 \times \mathrm{g}$ at $4^{\circ} \mathrm{C}$ for $5 \mathrm{~min}$ to remove unlysed erythrocytes. The relative hemoglobin content of the supernatants was assessed by measuring their optical density at $540 \mathrm{~nm}$ using an automated microtiter plate spectrophotometer. Values for maximum $(100 \%)$ and minimum hemolysis were obtained by adding $50 \mu \mathrm{L}$ of distilled water or HBSS to $25 \mu \mathrm{L}$ samples of RRBC. The degree of hemolysis $(Y)$ (percentage of hemolytic activity with respect to the maximum) was calculated, and a lysis curve for each sample was obtained by plotting $Y /(1-Y)$ against the volume $(\mathrm{mL})$ of plasma added on a $\log _{10}-\log _{10}$-scaled graph. For each experimental group, the volume of plasma producing $50 \%$ hemolysis $\left(\mathrm{ACH}_{50}\right)$ was determined, and the number of $\mathrm{ACH}_{50}(50 \%$ hemolysis $/ \mathrm{ml}$ serum $)$ units $/ \mathrm{mL}$ was calculated. The data are presented herein as ratios of the $\mathrm{FW}$ fish as mean $\pm \mathrm{SD}(n=5)$.

\section{Statistical analyses}

Experimental data are presented as mean $\pm \mathrm{SD}$. Comparisons between control and treatments were examined by one-way ANOVA followed by least square difference (LSD) $t$-tests (SAS 2004). Differences among treatment groups at different times were tested using the least significant difference test. An asterisk (*) denotes a $P$-value $<0.05$, indicating a significant difference compared with the control group.

\section{Results}

\section{Lysozyme activity}

As shown in Fig. 1A, production of lysozyme activity in plasma was increased $(P<0.05)$ at $1 \mathrm{~h}$ and $30 \mathrm{~h}$ after SW transfer, but was decreased $10 \mathrm{~h}$ after SW transfer. One sample of HK tissue was insufficient for lysozyme analysis; hence, three HK tissue samples were pooled in this assay. Profile of HK lysozyme activity (Figs. 1A and B) correlated with lysozyme activity of plasma.

\section{Alternative complement activity}

Complement activity in plasma was analyzed after the transference of tilapia to $24 \mathrm{psu}$ SW. After $1 \mathrm{~h}$, complement activity was decreased compared with FW controls. Surprisingly, after $10 \mathrm{~h}$, complement activity was increased compared with FW controls, even though this trend was not sustained through $30 \mathrm{~h}$ (Fig. 2). 

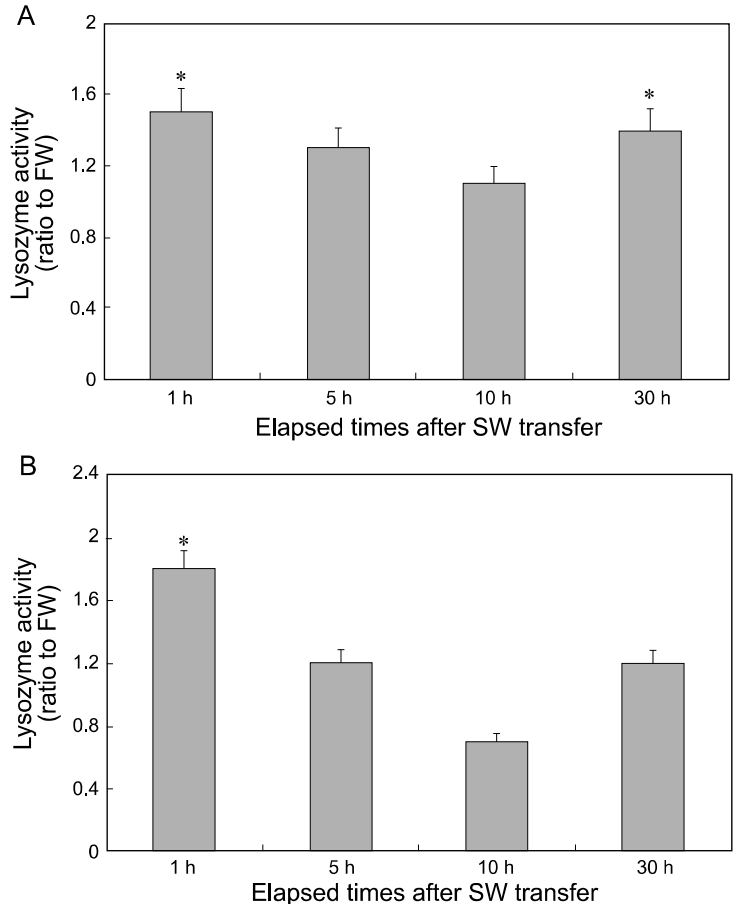

Fig. 1. In vivo lysozyme activity in (A) plasma and (B) HK after tilapia were exposed to 24 psu SW for 1, 5,10 and $30 \mathrm{~h}$. Data are expressed as mean $\pm \mathrm{SD}$ $(n=5)$. Asterisk denotes $P$ value $(P<0.05)$, which means the data are significantly different from the control group.

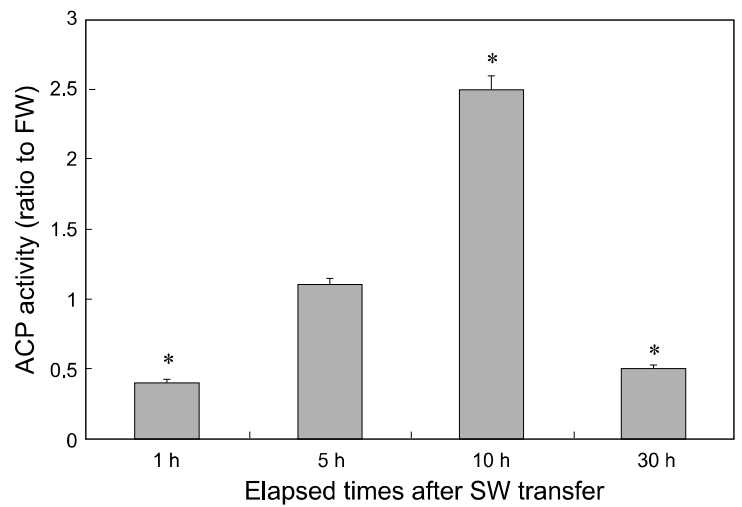

Fig. 2. In vivo plasma ACP activity after tilapia were exposed to $24 \mathrm{psu} \mathrm{SW}$ for $1,5,10$, and $30 \mathrm{~h}$. Data are expressed as mean $\pm \mathrm{SD}(n=5)$. Asterisk denotes $P$ value $(P<0.05)$, which means the data are significantly different from the control group.

\section{Immune responses by $\mathrm{HK}$ cells after $\mathrm{SW}$ transfer}

Phagocytic capacity, measured as the intensity of fluorescence, was increased $5 \mathrm{~h}$ after SW transfer in HK (Fig. 3A). Respiratory burst activity was significantly increased at $10 \mathrm{~h}(P<0.005)$ and signifiantly decreased at $30 \mathrm{~h}$ after SW transfer (Fig. 3B).
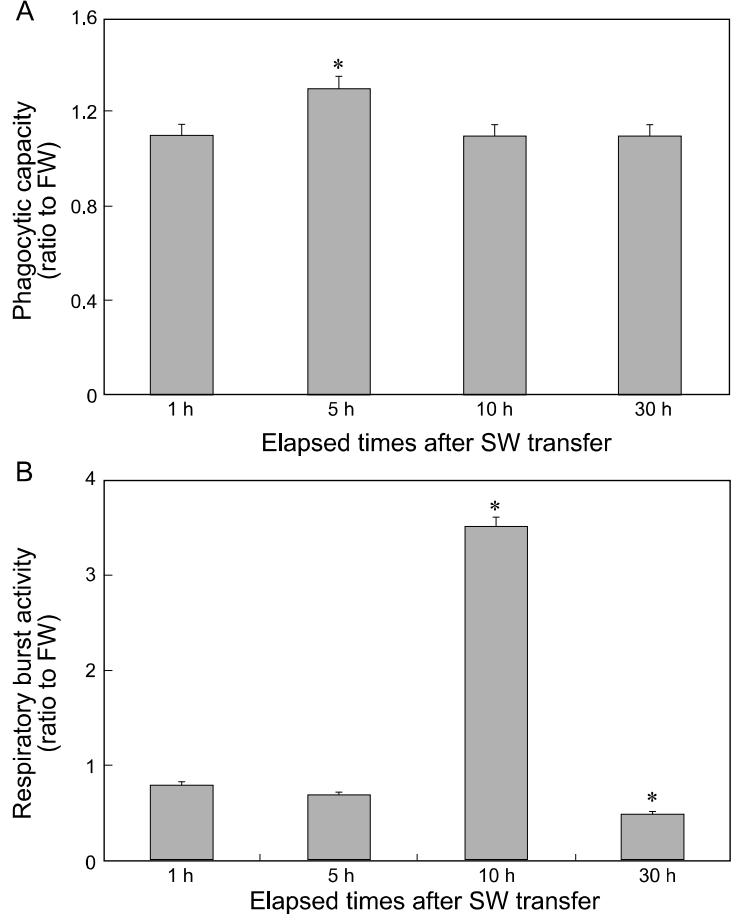

Fig. 3. In vivo cellular parameters of HK: (A) phagocytosis capacity measured as intensity of fluorescence; (B) respiratory burst activity (intensity of respiratory burst) after tilapia exposure to 24 psu SW for 1, 5, 10 and $30 \mathrm{~h}$. Asterisk denotes $P$ value $(P<0.05)$, which means the data are significantly different from the control group.

\section{Immune response by splenocytes following SW transfer}

Phagocytic capacity was increased $1 \mathrm{~h} \quad(P<0.05)$ after SW transfer (Fig. 4A). Intensity of respiratory burst activity was elevated at $10 \mathrm{~h}(P<0.05)$, but decreased at $30 \mathrm{~h}$ after SW transfer (Fig. 4B).

\section{Discussion}

Many species of fish suffer stress responses to sudden transfer from FW to SW, and stress is often associated with the suppression of immune parameters. In non-smolting salmonids, FW-SW and FWFW transfer resulted in a typical acute stress response characterized by a marked increase in plasma cortisol concentration (Taylor et al., 2007). The concentrations of cortisol and plasma osmolality are increased markedly after transfer from FW to SW and exhibit a significant positive correlation (Kajimura et al., 2004). However, tilapia are reported to be capable of direct transfer from FW to 25 psu SW with certain physiological effects (Weng et al., 2002), but there is 

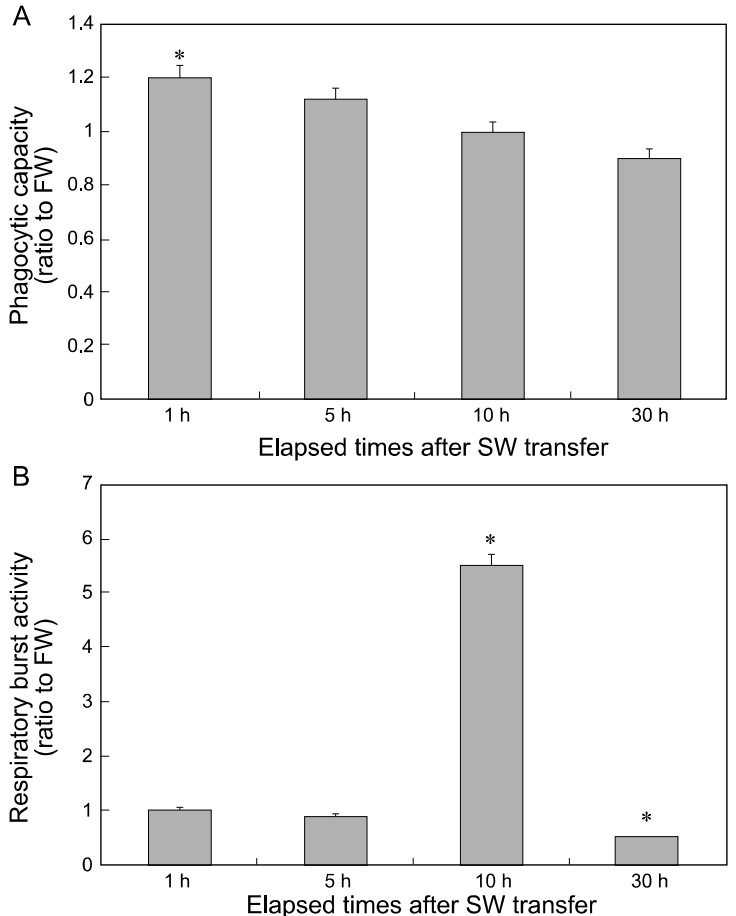

Fig. 4. In vivo cellular parameters of spleen: (A) phagocytosis capacity measured as intensity of fluorescence; (B) respiratory burst activity (intensity of respiratory burst) after tilapia exposure to $24 \mathrm{psu}$ SW for $1,5,10$ and $30 \mathrm{~h}$. Data are expressed as mean $\pm \mathrm{SD}(n=5)$. Asterisk denotes $P$ value $(P<0.05)$, which means the data are significantly different from the control group.

no available information on the effects of such transfer on innate immune parameters. The present study was thus conducted to investigate the effects of salinity stress on the innate immune responses of tilapia.

In general, humoral innate factors like lysozyme and complement are important antimicrobial factors. The greatest concentration of lysozyme activity is found in the HK of fish due to the HK's high numbers of leukocytes (Marc et al., 1995; Lee et al., 1998; Takahashi et al., 1986; Yousif, et al., 1991; Roed et al., 1993). Nile tilapia cultured in $24 \mathrm{psu}$ salinity for 2 and 4 weeks, or in 12 psu salinity for 4 weeks, showed increased lysozyme activity (Dominguez, et al., 2005). In our study, plasma and HK lysozyme activity were increased at 1, 5, and $30 \mathrm{~h}$ after tilapia were transferred to SW. Surprisingly, the lowest lysozyme activity was observed $10 \mathrm{~h}$ after SW transfer, and this was correlated with an increase in plasma ACP activity. ACP, a non-specific humoral parameter, exhibits lytic, proinflammatory, chemotactic, and opsonic activities in teleosts (Ellis, 1999).
Following acute stress in teleosts, both enhancement and suppression of plasma lysozyme activity have been reported depending on the type, intensity, and duration of the stressor (Fevolden et al., 2003). However, the exact mechanisms by which both lysozyme and ACP activities can show opposite responses depending on stress conditions remains to be studied further.

The phagocytic activity of head kidney leukocytes increased in brown trout (Salmo trutta) transferred from FW to SW (Marc et al., 1995), whereas in the present study, we found that tilapia HK leukocytes and spleen cells exhibited no detectable changes in phagocytosis compared with control fish after $24 \mathrm{psu}$ SW transfer. Alteration in the numbers and composition of circulating leukocytes is an indicator of acute and chronic stress (Barton and Iwama, 1991). When phagocytic capacity was compared between HK leucocytes and splenocytes, an increase in splenocyte phagocytic capacity was observed after $1 \mathrm{~h}$ of SW transfer, but increases in HK phagocytic capacity were found only after $5 \mathrm{~h}$ of SW transfer. These facts suggest that a hyperosmotic medium can induce phagocytic activity in tilapia at earlier elapsed times after SW transfer.

Non-smolting rainbow trout $\mathrm{HK}$ immune cells showed greater respiratory burst activity (approximately $50 \%$ higher) when transferred to $\mathrm{SW}$ (Taylor et al., 2007). It has been reported previously that stress affects the phagocytic and/or respiratory burst activity of spleen, head kidney and blood leucocytes (Thompson et al., 1993; Pulsford et al., 1994; Vazzana., 2002; Liebert and Shreck, 2006). In our experiments, the respiratory burst activities of tilapia HK leucocytes and spleen cells were increased after $10 \mathrm{~h}$ of SW transfer. These results were similar to those for ACP. However, further studies should be performed to investigate whether respiratory burst activity is correlated with ACP in tilapia after SW transfer.

The values of each immune parameter measured at different elapsed times after SW transfer did not show constant increases. However, the transfer of $O$. niloticus from $\mathrm{FW}$ to $\mathrm{SW}$ caused partial increases at specific SW transfer times in various immune parameters, suggesting that the exposure of tilapia to hyperosmotic conditions has an immunostimulatory effect on these innate cellular and humoral immune parameters.

\section{Acknowledgements}

This work was financially supported by a grant 
from the Fisheries Science Institute, Kunsan National University in 2010.

\section{References}

Barton B and Iwama GK. 1991. Physiological changes in fish from stress in aquaculture with emphasis on the response and effects of corticosteroids. Ann Rev Fish Dis 10, 3-26.

Craig S, Lopez A, Hoskin D and Markham F. 2005. Meconium inhibits phagocytosis and stimulates respiratory burst in alveolar macrophages. Ped Res 57, 813-818.

Crawshaw LI. 1979. Responses to rapid temperature change in vertebrate ectotherms. Amer Zool 19, 225237.

Cuesta A, Laiz-Carrión R, Del Río MP, Meseguer J, Mancera JM and Esteban MA. 2005. Salinity influences the humoral immune parameters of gilthead seabream (Sparus aurata L.). Fish Shellfish Immunol $18,255-261$.

Dominguez M, Takemura A and Tsuchiya M. 2005. Effects of changes in environmental factors on the nonspecific immune response of Nile tilapia, Oreochromis niloticus L. Aquat Res 36, 391-397.

Ellis AE. 1999. Immunity to bacteria in fish. Fish Shellfish Immunol 9, 291-308.

Esteban MA, Mulero V, Munoz J and Meseguer J. 1998. Methodological aspects of assessing phagocytosis of Vibrio anguillarum by leucocytes of gilthead sea-bream (Sparus aurata L.) by flow cytometry and electron microscopy. Cell Tissue Res 293, 133-141.

Fevolden SE, Røed KH and Fjalestad K. 2003. A combined salt and confinement stress enhances mortality in rainbow trout (Oncorhynchus mykiss) selected for high stress responsiveness. Aquaculture 216, 67-76.

Jaso-Friedmann L, Ruiz J, Bishop GR and Evans DL. 2002. Regulation of innate immunity in tilapia: activation of nonspecific cytotoxic cells by cytokine-like factors. Dev Comp Imm 24, 25-36.

Kajimura S, Hirano T, Moriyama S, Vakkuri O, Leppäluoto J and Grau EG. 2004. Changes in plasma concentrations of immunoreactive ouabain in the tilapia in response to changing salinity: is ouabain a hormone in fish? Gen Comp Endocrin 135, 90-99.

Lee TH, Tsai JC, Fang MJ, Yu MJ and Hwang PP. 1998. Isoform expression of $\mathrm{Na}^{+}-\mathrm{K}^{+}$- ATPase alpha-subunit in gills of the teleost Oreochromis mossambicus. Amer J Physiol 275. R926-R932.

Liebert AM and Shreck CB. 2006. Effect of acute stess on osmoregulation, feed intake, IGF-I, and cortisol in yearling steelhead trout (Oncorhynchus mykiss) during seawater adaptation. Gen Comp Endocrin 148, 195-202.
Lie O, Evensen, Sorensen A and Froysadal E. 1989. Study on lysozyme activity in some fish species. Dis Aquat Org 6, 1-5.

Marc A, Quentel C, Severe A, Le Bail PY and Boeuf G. 1995. Changes in some endocrinological and nonspecific immunological parameters during seawater exposure in the brown trout. J Fish Biol 46, 1065-1081.

Prabakaran M, Binuramesh C, Steinhagen D and Michael RD. 2007. Immune response in the tilapia, Oreochromis mossambicus on exposure to tannery effluent. Ecotox Envir Safety 68, 372-378.

Pulsford AL, Gony SL, Tomlinson M, Collingwood and Glynn PJ. 1994. Effects of acute stress on the immune system of the dab (Limanda limanda). Comp Bio-chem Physiol 109, 129-139.

Roed KH, Larsen HJS, Linder RD and Refstie T. 1993. Genetic variation in lysozyme activity in rainbow trout (Oncorhyncus mykiss). Aquaculture 109, 237-244.

Shugar D. 1952. The measurement of lysozyme activity and the ultra-violet inactivation of lysozyme. Bio-chem Biophysica Acta 8, 302-309.

Takahashi Y, Itami T and Konegawa K. 1986. Enzymatic properties of partially purified lysozyme from the skin mucus of carp. Bull Japan Soc Sci Fisheries 52, 12091214

Taylor F, Needham MP, North BP, Morgan A, Thompson $\mathrm{K}$ and Migaud H. 2007. The influence of ploidy on saltwater adaptation, acute stress response and immune function following seawater transfer in non-smolting rainbow trout. Gen Comp Endocrin 152, 314-325.

Taylor SL, L Jaso-Friedmann, Allison AB, Eldar A and Evans DL. 2001. Streptococcus iniae inhibition of apoptosis of nonspecific cytotoxic cells: a mechanism of activation of innate immunity in teleosts. Dis Aquat Org 46, 15-21.

Thompson I, White A, Fletcher TC, Houlihan DF and Secombes CJ. 1993. The effect of stress on the immune response of Atlantic salmon (Salmo salar L.) fed diets containing different amounts of vitamin C. Aquaculture 114, 1-18.

Vazzana M, Cammarata M, Cooper EL and Parrinello N. 2002. Confinement stress in sea bass (Dicentrarchus labrax) depresses peritoneal leukocyte cytotoxicity. Aquaculture 210, 231-243.

Weng CF, Chia-Chang C, Gong HY, Chen MHC, Lin CJF and Huang WT. 2002. Acute changes in gill $\mathrm{Na}^{+}-\mathrm{K}^{+}$ ATPase and creatine kinase in response to salinity changes in the euryhaline teleost, tilapia (Oreo-chromis mossambicus). Physiol Biochem Zool 75, 29-37.

Yousif AN, Albright LJ and Evelyn TPT. 1991. Occurrence of lysozyme in the eggs of coho salmon Oncorhynchus kisutch. Dis Aquat Org 10, 45-49. 
(Received 19 July 2010; Revised 2 September 2010; Accepted 6 December 2010) 